\title{
Successful recommissioning of community diabetes services in West Hampshire
}

\author{
KATE FAYERS, HERMIONE PRICE
}

\begin{abstract}
Introduction: The West Hampshire Community Diabetes Service replaced traditional hospital-based diabetes outpatients in 2010 and has been successfully recommissioned, one of the first community diabetes services to complete the commissioning cycle.

Method: The successful introduction of traditional diabetes services into the community requires clear leadership and a strategic vision. Unlike many hospital-based services, the community setting is at the frontline of Clinical Commissioning Group (CCG) targets for recommissioning. Thus, the threat of change is relentless and must be embraced rather than feared. As a result, the community setting can offer a new approach to the management of long-term conditions, with healthier and more productive partnerships between healthcare professionals and patients. We have identified four success criteria: skills for leadership, strategic vision, stakeholder partnerships, and shared learning.

Results: The success of the diabetes service redesign in West Hampshire is reflected in successful recommissioning of the service by the West Hampshire CCG. This is one of the first such services to be successfully recommissioned in the country.

Conclusions: Relocating general diabetes services into the community has been a catalyst for improved integration between specialist and primary care in West Hampshire. The process of service redesign and recommissioning is not widely communicated between consultant diabetologists, who will be pivotal to developing and delivering high-quality community care. Communicating these messages to doctors in training will ensure newly-appointed consultants have the skills required to lead change in local diabetes services and ensure high performing services are recommissioned successfully.

Br J Diabetes Vasc Dis 2015;15:127-130
\end{abstract}

West Hampshire Community Diabetes Service, Lyndhurst, UK

Address for correspondence: Dr Kate Fayers

West Hampshire Community Diabetes Service, Long Term Condtions

Centre, Fenwick 2, Pikes Hill, Lyndhurst, SO43 7NG, UK.

Tel: +44 (0)2380 286401

E-mail: Kate.Fayers@southernhealth.nhs.uk

http://dx.doi.org/10.15277/bjdvd.2015.027
Key words: commissioning, recommissioning, service redesign, community diabetes, clinical leadership

The case for community care

The National Health Service (NHS) is currently in the midst of a funding crisis. ${ }^{1}$ Its recently published five-year forward view emphasises the need to improve efficiency to deliver safe effective high-quality care to those who need it. ${ }^{2}$ In addition, the full potential of community services has yet to be realised. ${ }^{3}$ At the same time, the number of people living with type 2 diabetes continues to rise. ${ }^{4}$

Available data support early, effective intervention to reduce the complications of diabetes.5,6 Ten percent of the NHS budget is spent on diabetes alone, of which $80 \%$ is spent on treating potentially avoidable complications. ${ }^{7,8}$ As a long-term condition, diabetes is often accompanied by multiple comorbidities such as heart failure and respiratory disease, and the number of people with multiple comorbidities is rising as the population of the UK ages. ${ }^{9}$ Patients with multiple comorbidities are more likely to be admitted acutely into hospital and to have a longer length of stay. ${ }^{10}$

In order to protect patients with diabetes, nine key care processes have been identified, ${ }^{11}$ including screening for neuropathy, retinopathy and renal disease. But, only $54 \%$ of patients achieve all nine tests, ${ }^{12}$ despite financial incentives for primary care. ${ }^{13}$

The traditional approach to diabetes care centres on the familiar medical model and is variously shared between the hospital-based, consultant-led diabetes team and the primary care team. A pyramid of need, sometimes poorly defined, gives the neediest patients access to specialist care. Specialist diabetes nurse provision (often for insulin-based treatment) has been available in many areas for some time. More recently, locality by locality, the traditional model has been challenged to varying degrees. ${ }^{14-16}$ Hospital-based diabetes consultants frequently contribute towards other aspects of acute trust functionality, particularly acute medical on-call, but also endocrinology and research. ${ }^{17}$ This plurality has made it difficult to liberate consultant diabetologists from the acute setting. Two workable options have emerged in the last few years: consultant outreach and whole scale community service redesign. In this article, we will describe our experience of establishing a whole scale service redesign in the community setting.

\section{Establishing the service}

The West Hampshire Community Diabetes Service (see Figure 1) was established in 2010 to provide community-based diabetes care 
Figure 1. The West Hampshire Community Diabetes Service team

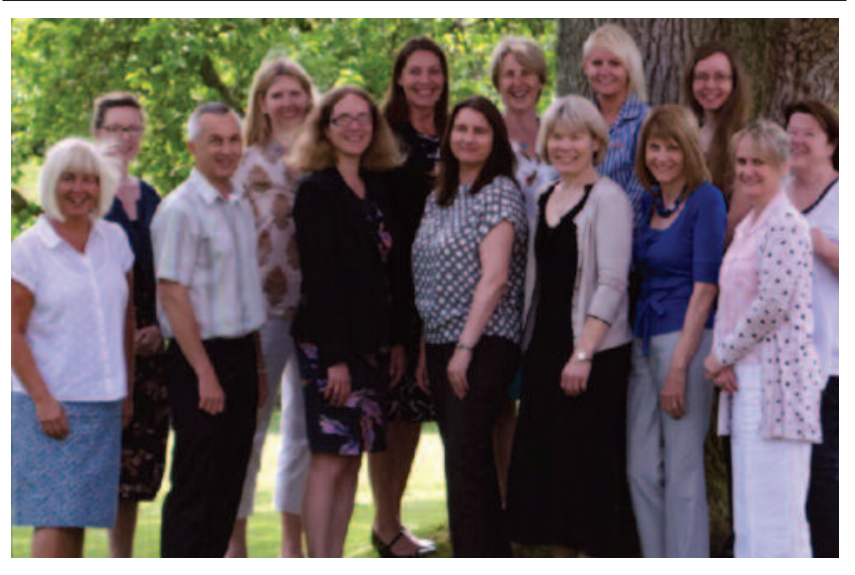

to a population of 19,000 patients with diabetes in the emerging West Hants Clinical Commissioning Group (CCG). The geography of the CCG is challenging and encompasses the New Forest, the city of Winchester, urban outskirts of Southampton and includes areas of deprivation. The new model replaced care at two acute trusts. Education of patients with type 1 or type 2 diabetes was also relocated into the community in order to replace patchy availability across the area.

The Chronic Care Model was used as a template to inform the development of the project. ${ }^{18}$ This evidence-based model comprises seven elements for successful management of longterm conditions. Later work has enabled these principles to be incorporated into the House of Care model. ${ }^{19}$ Adherence to the Chronic Care Model led us to re-examine the traditional approach to patients with diabetes and focused our efforts on deliberately developing a collaborative approach to working alongside patients in order to achieve their personal goals.

The learning curve was steep and required the rapid implementation of a new clinical database (adapted from a neighbouring trust) in order to become paper-free and establish remote access to patient records. Six community computing criteria were identified (Box 1). The portfolio of educational courses available for health care professionals and patients has grown significantly. We recently launched a prospectus of community-based courses. For patients, these included type 1 diabetes structured education, type 2 diabetes education for the newly-diagnosed, carbohydrate awareness, and carbohydrate

Box 1. Six community computing criteria

1. Clinical database of medications, letters etc.

2. Remotely accessible

3. Auditable

4. Integrated pathology results

5. GP letter generated (auto populated with data)

6. Communication notepad for the team counting. For healthcare professionals, we provided education on insulin for non-registered practitioners, and ongoing education for general practitioners and practice nurses.

The service replaced outpatient activity at two local acute trusts. Outpatient clinics are provided at 11 locations across West Hampshire and approximately 200 consultant-led clinics per year take place. All clinics are multidisciplinary with a diabetes specialist nurse and a diabetes specialist dietitian clinic taking place alongside consultant-led clinics.

\section{Developing the service}

We identified four success criteria for developing a community service: skills for leadership, strategic vision, stakeholder partnerships, and shared learning.

\section{Skills for leadership}

Good leadership is an essential component of any clinical service. The dynamics of change and the need for rapid implementation of new innovation magnify the effect of good or bad leadership. All team members have been involved in development work, in keeping with a trust-wide approach to proactive leadership development. Three senior team members have completed a residential leadership course (extended to all senior leaders across the trust), junior team members have participated in Myers Briggs type indicator questionnaires ${ }^{20}$ and we hold twice-yearly team away days. Staff members are encouraged to be self-aware and responsive to other team members. This level of investment is seen as essential rather than an indulgence, with benefits that include clear identification of roles and responsibilities, good team communication and feedback, effective performance management, talent identification and succession planning. The Southern Health NHS Foundation Trust was awarded the Guardian Leadership Award in 2013. ${ }^{21}$

\section{Strategic vision}

The team developed a mission statement this year (Box 2) based on industry research focused on the importance of identifying "why" we work in a given way and communicating this effectively to increase engagement, rather than the functional "what" we do. As part of the process of recommissioning, we looked again at our clinical model, embracing the opportunity to enhance our existing structure. The Chronic Care Model and House of Care Model formed the foundation and dissecting each element in turn enabled us to ensure that we achieved a holistic solution.

Box 2. Our vision: Why work for a community diabetes service?

To ensure that all people with diabetes have access to excellent skills and knowledge, so that they can achieve their individual goals and become active participants in their care wherever possible.

\section{Stakeholder partnerships}

We identified four key stakeholders: patients, local practices, acute Trusts, and the local CCG. We have consistently worked with our stakeholder partners, listening to feedback and building relationships 
through mutual understanding and a collaborative approach. Patient engagement has been positive and enabled us to develop an active stakeholder group which has contributed to local steering group meetings and helped to co-develop a new care plan. We will be working with patients throughout 2015 to help launch a CCG-wide social movement which will make it easier for patients to contribute and comment on all aspects of our service.

\section{Shared learning}

Qualitative and quantitative feedback enables us to accurately measure our activity and identify areas of concern early. We identified the importance of sharing this learning across the wider healthcare system in order to reduce variability. In the clinical model described below, we have incorporated mechanisms for reflecting back primary care metrics against a CCG benchmark.

\section{Costs and outcomes}

Changes to triage pathways have reduced new follow-up ratios by one-third and generated increased capacity to support primary care. Comparing costs for a community service (block contract) with an acute hospital service (Payment by Results) is not easy, but the value of the contract compared with a tariff-based system suggests a $30 \%$ reduction in cost is possible.

\section{Recommissioning}

The service was given notice in 2014, in keeping with the end of the existing contract. Providers were invited to bid for the service under "Any Qualified Provider".22 This opened up not just local but potentially national competition from both NHS and private providers. The commissioning spotlight has focused heavily on community diabetes services since the transformation of community services programme was launched by the government in 2008. ${ }^{3}$ This is a new experience for newly-qualified consultants and may explain why some community-based consultant posts have not appeared to be attractive career options. To our knowledge, specialist registrars receive little opportunity to engage in community-based training and no opportunity to develop a skill set that will support the commissioning process. Our preparation commenced early, and comprised an estimated 100 hours of consultant time alone. Fortunately, our service was successfully recommissioned. However, the nature of the competitive bid process will inevitably mean that some consultant diabetologists will invest similarly without a positive outcome, potentially losing hundreds of consultant hours from an already squeezed clinical system.

In order to better prepare specialist trainees for their future role in commissioning and recommissioning diabetes services, we are working with colleagues from the Wessex Deanery to develop the local training programme to allow trainees to spend time with our community service. The aim of this time is to allow trainees to develop a better understanding of how and why diabetes services are commissioned and recommissioned and the local drivers for this. During this period the trainees will spend time with key local stakeholders in diabetes including commissioners, primary care and public health colleagues.

\section{Our clinical model}

The model deliberately follows a cyclical approach, clearly mirroring the Plan Do Study Act approach to service improvement. ${ }^{23}$ The primary care localities (Practice Makes Perfect localities) are divided between named diabetes specialist nurses. Diabetes specialist nurses are encouraged to take ownership of their locality, reporting back on outcomes and identifying local educational opportunities for practice nurses.

Each practice receives an annual peer review visit and a copy of their local metrics. The metrics, an agreed diabetes action plan and tailored diabetes specialist nurse support form the basis of a practice tool kit (Box 3). Additional tools include an educational DVD for new type 2 diabetes patients and a matching care plan, the "Chatty Plan".

Box 3. Practice diabetes toolkit

- Practice makes perfect localities: named diabetes specialist nurse, ownership of locality, clustering of practice nurse education

- Annual metrics: Public Healh England Healthier Lives data24

- Annual diabetes action plan: a mutually agreed action plan, shared with the community diabetes service and CCG

\section{Conclusions}

Relocating general diabetes services into the community has been a catalyst for improved integration between specialist and primary care in West Hampshire. The process of service redesign and recommissioning is not widely communicated between consultant diabetologists who will be pivotal to developing and

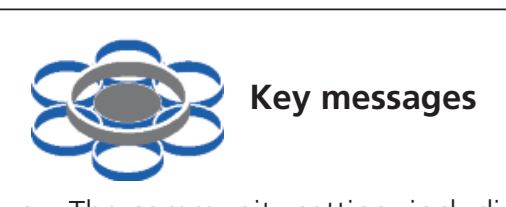

- The community setting, including community diabetes care, is at the frontline of Clinical Commissioning Group (CCG) targets for recommissioning

- The West Hampshire Community Diabetes Service was established in 2010 to provide community-based diabetes care to $\sim 19,000$ diabetes patients across a diverse area including challenging areas of socioeconomic deprivation

- Our model for achieving successful recommissioning was based on four clearly defined success criteria for developing a community service: skills for leadership, strategic vision, stakeholder partnerships, and shared learning

- We describe a model for achieving successful recommissioning of the service that may be applicable to other community diabetes services in the future 
delivering high-quality community care. Communicating these messages to doctors in training will ensure that newly-appointed consultants have the skills required to lead change in local diabetes services and that high-performing services are successfully recommissioned.

\section{Conflict of interest None Funding None}

\section{References}

1. The King's Fund (2014) Commission on the Future of Health and Social Care in England. Available at: http://www.kingsfund.org.uk/projects/commission-future-health-and-social-care-england?gclid=CICbgrbgvsQC FUL4wgodu20AzA (accessed March 2015)

2. NHS England (2014) Five Year Forward View. Available at: http://www.england.nhs.uk/wp-content/uploads/2014/10/5yfv-web.pdf (accessed March 2015)

3. The Kings Fund (2014) Community Services. Available at: http://www.kingsfund.org.uk/publications/community-services (accessed March 2015)

4. Diabetes UK (2015) State of the Nation Challenges for 2015 and Beyond. Available at: http://www. diabetes.org.uk/Documents/About\%20Us/ What $\% 20$ we $\% 20$ say/State $\% 20$ of $\% 20$ the $\% 20$ nation $\% 202014$.pdf (accessed March 2015)

5. Holman RR, Paul SK, Bethel MA, Neil HA, Matthews DR. UKPDS 81 longterm follow-up after tight control of blood pressure in type 2 diabetes. N Engl J Med 2008;359:1565-76. http://dx.doi.org/10.1056/NEJMoa0806359

6. Holman RR, Paul SK, Bethel MA, Matthews DR, Neil HA. UKPDS 8010 year follow-up of intensive glucose control in type 2 diabetes. $N$ Engl J Med 2008;359:1577-89. http://dx.doi.org/10.1056/NEJMoa0806470

7. Hex N, Bartlett C, Wright D, Taylor M, Varley D. Estimating the current and future costs of Type 1 and Type 2 diabetes in the UK, including direct health costs and indirect societal and productivity costs. Diabet Med 2012;29:855-62. http://dx.doi.org/10.1111/j.1464-5491.2012.03698.x

8. Diabetes UK (2014) The Cost of Diabetes. Available at: http://www.diabetes.org.uk/Documents/Diabetes \%20UK\%20Cost\%20of\%20Diabetes\%20Report.pdf (accessed March 2015)

9. Guthrie B, Payne K, Alderson P, McMurdo ME, Mercer SW. Adapting clinical guidelines to take account of multimorbidity. BMJ 2012;345 e6341. http://dx.doi.org/10.1136/bmj.e6341

10. National Institute for Health and Care Excellence (2014) Multimorbidity: the assessment, prioritisation and management of care for people with commonly occurring multimorbidity. Available at: http://www. nice.org.uk/guidance/gid-cgwave0704/resources/multimorbidity-scopeconsultation-document2 (accessed March 2015)
11. National Institute for Health and Care Excellence. Clinical Guidance on Diabetes CG15: Type 1 diabetes: Diagnosis and management of type 1 diabetes in children, young people and adults and CG66:Type 2 diabetes: the management of type 2 diabetes (update). https://www.nice.org.uk/ guidance/cg15

12. National Diabetes Audit Executive Summary 2009-2010. Available at: http://www.hqip.org.uk/assets/NCAPOP-Library/National-Diabetes-AuditExecutive-Summary-2009-2010.pdf (accessed March 2015)

13. National Institute for Health and Care Excellence. Quality Outcome Framework (QOF). Available at: https://www.nice.org.uk/standards-andindicators/qofindicators\#/?categories=3896\&page $=1$ (accessed March 2015)

14. Partha Kar. The Super Six model: Integrating diabetes care across Portsmouth and south-east Hampshire. Diabetes \& Primary Care 2012;14 277-83.

15. Nuffield Trust (2013). Evaluation of the first year of the Inner North West London Integrated Care Pilot. Available at: http://www. nuffieldtrust.org.uk/sites/files/nuffield/publication/evaluation_of_the_first _year_of_the_inner_north_west_london_integrated_care_pilot.pdf (accessed March 2015)

16. Rea RD, Gregory S, Browne M, et al. Integrated diabetes care in Derby new NHS organisations for new NHS challenges. Available at http://www.practicaldiabetes.com/SpringboardWebApp/userfiles/m espdi/file/September\%202011/Rea\%20online\%20+\%20charts.pdf (accessed March 2015)

17. ABCD/Diabetes UK/RCP Diabetes and Endocrinology National Manpower Report (Consultant Survey for the year ending 30th September 2013). Available at: http://www.diabetes.org.uk/Documents/Reports/abcd-dukrcp-manpower-report-2013-0214.pdf (accessed March 2015)

18. Wagner EH. Chronic disease management: What will it take to improve care for chronic illness? Effective Clinical Practice 1998;1:2-4

19. NHS England. Enhancing the quality of life for people living with long term conditions- The House of Care. Available at: http://www.england.nhs.uk/house-of-care/ (accessed March 2015)

20. The Myers Briggs Foundation. Available at: http://www.myersbriggs.org/ my-mbti-personality-type/mbti-basics/ (accessed March 2015)

21. http://www.theguardian.com/healthcare-network/2013/oct/25/southernhealth-foundation-trust-leadership-award-winner (accessed March 2015)

22. Department of Health (2011) Operational guidance to the NHS: Extending Patient Choice of Provider. https://www.gov.uk/government/publications/operational-guidance-to-the-nhs-extending-patient-choice-of-provi der--2

23. NHS Institute for Innovation and Improvement. Quality and Service Improvement Tools Plan, Do, Study, Act (PDSA). Available at http://www.institute.nhs.uk/quality_and_service_improvement_tools/quality_and_servic e_improvement tools/plan do study_act.html (accessed March 2015)

24. Public Health England. Healthier Lives: Diabetes. Available at: http://healthierlives. phe.org.uk/ (accessed March 2015)

\section{Invasive Staphylococcus aureus infections in diabetes mellitus}

(Br J Diabetes Vasc Dis 2013;13:164-177. http://dvd.sagepub.com/content/13/4/164.full.pdf+html)

\section{LUKMAN HAKEEM, ROBERT BS LAING, IVAN TONNA, JOHN G DOUGLAS, AND ALEXANDER R MACKENZIE}

The editors of BJDVD had an issue of suspected plagiarism highlighted to them by our previous publishers SAGE. A reader had noted that in the paper above, there may be an issue of plagiarism due to the inclusion of unattributed material from a medical textbook http://www.mhprofessional.com/downloads/products/0071702938/35_kasper_ch35_p386-399.pdf which had not been referenced.

Following COPE guidance, the lead author on this paper was contacted and has apologised on behalf of his co-authors for mistakenly and unintentionally omitting references to the original work. 